\title{
Benzylic C-H Azidation Using the Zhdankin Reagent and a Copper Photoredox Catalyst
}

DOI:

10.1021/acs.orglett.6b00512

\section{Document Version}

Accepted author manuscript

Link to publication record in Manchester Research Explorer

\section{Citation for published version (APA):}

Rabet, P., Fumagalli, G., Boyd, S., \& Greaney, M. (2016). Benzylic C-H Azidation Using the Zhdankin Reagent and a Copper Photoredox Catalyst. Organic Letters, 18(7), 1646-1649. https://doi.org/10.1021/acs.orglett.6b00512

\section{Published in:}

Organic Letters

\section{Citing this paper}

Please note that where the full-text provided on Manchester Research Explorer is the Author Accepted Manuscript or Proof version this may differ from the final Published version. If citing, it is advised that you check and use the publisher's definitive version.

\section{General rights}

Copyright and moral rights for the publications made accessible in the Research Explorer are retained by the authors and/or other copyright owners and it is a condition of accessing publications that users recognise and abide by the legal requirements associated with these rights.

\section{Takedown policy}

If you believe that this document breaches copyright please refer to the University of Manchester's Takedown Procedures [http://man.ac.uk/04Y6Bo] or contact uml.scholarlycommunications@manchester.ac.uk providing relevant details, so we can investigate your claim.

\section{OPEN ACCESS}




\title{
Benzylic C-H Azidation Using the Zhdankin Reagent and a Copper Photoredox Catalyst
}

\author{
Pauline T. G. Rabet ${ }^{\dagger}$, Gabriele Fumagalli, ${ }^{\dagger}$ Scott Boyd ${ }^{\ddagger}$, Michael F. Greaney ${ }^{\dagger} *$ \\ 'School of Chemistry, University of Manchester, Oxford Road, Manchester, UK, M13 9PL, UK \\ * Department of Oncology, AstraZeneca, Alderley Park, Macclesfield, SK10 4TG, UK
}

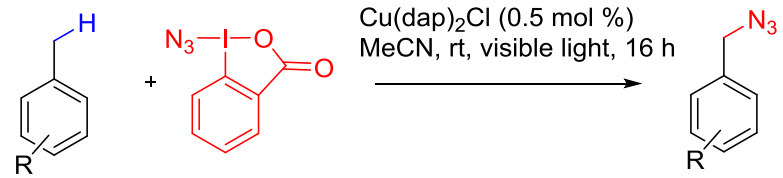

30 examples

\begin{abstract}
An azidation method for C-N bond formation at benzylic C-H positions is described using copper-catalyzed visible light photochemistry and the Zhdankin azidoiodinane reagent. The method is applicable to a wide range of substrates bearing different functional groups and having a primary, secondary or tertiary benzylic position, and is thought to proceed through a radical chain reaction.
\end{abstract}

The use of copper complexes in visible light photocatalysis (PRC) is a growing area of research, driven in part by the huge cost differential between copper and commonly-used photoredox catalysts based on iridium and ruthenium Noble metals. ${ }^{1,2}$ We have recently developed photoredox-catalyzed azidation chemistry using the Zhdankin azidoiodinane reagent ${ }^{3}(\mathbf{1})$ and the Sauvage catalyst $\mathrm{Cu}(\text { dap })_{2} \mathrm{Cl}$ (dap $=2,9$-bis $(p$-anisyl)-1,10phenanthroline), ${ }^{4}$ which reacted smoothly with alkenes in alcohol solvents to give a range of alkoxy-azidated products (Scheme 1$).^{5}$ The compatibility of this versatile azidation reagent with copper PRC, under mild conditions, motivated us to investigate new $\mathrm{C}-\mathrm{N}$ bond forming applications.

The Zhdankin reagent is increasingly being used as a versatile azidation reagent, with recent reports describing $\mathrm{C}-\mathrm{N}$ bond formation at aliphatic tertiary and secondary $\mathrm{C}-\mathrm{H}$ positions ${ }^{6}$ (iron and ruthenium catalysis), ${ }^{7}$ arenes (copper catalysis), ${ }^{8} \beta$ keto esters, ${ }^{9}$ aldehydes (iodide catalysis), ${ }^{10}$, and alkenes. ${ }^{5,11,12}$ We chose to investigate $\mathbf{1}$ in benzylic $\mathrm{C}-\mathrm{H}$ azidation, as classic approaches to this useful motif, starting from $\mathrm{C}-\mathrm{H}$ groups, use nucleophilic azide and strong oxidizing agents, and are necessarily restricted to electron rich substrates. ${ }^{13}$ More recent work on direct $\mathrm{C}-\mathrm{H}$ azidation has featured a small number of benzylic azidations, but is restricted to electron-rich secondary and tertiary substrates. ${ }^{7,12 b} \mathrm{We}$ wondered if a combination of the Zhdankin reagent (an electrophilic azide source) and copper photoredox catalysis could deliver benzylic azides $\mathbf{5}$ across a wider range of substrates, particularly in the more challenging primary series.

We began by screening simple toluene derivatives and were pleased to obtain an encouraging result with para-xylene, obtaining an $80 \%$ yield of the azidated product 3a using one equivalent of 1 and $\mathrm{Cu}(\mathrm{dap})_{2} \mathrm{Cl}(1 \mathrm{~mol} \%)$ in a mixture of acetonitrile and para-xylene (1:1) (Table 1$)$. The reaction was completely selective for the benzylic position, an important distinction, as arene azidation has been reported for toluidine
Scheme 1. Proposed benzylic C-H azidation.

Previous azidation chemistry with 1

1. Photoredox catalysed alkene azidation

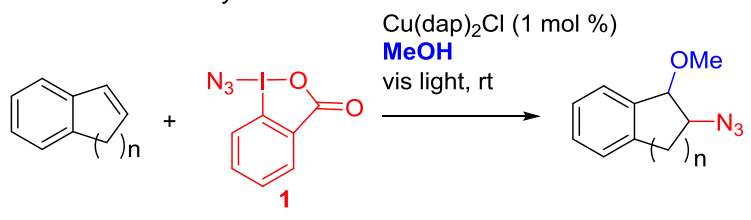

2. Metal-catalysed aliphatic $\mathrm{C}-\mathrm{H}$ azidation

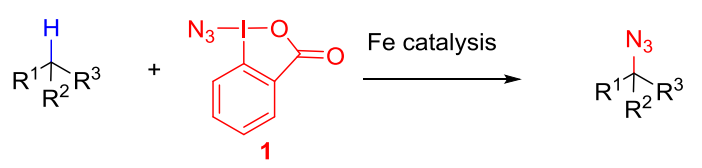

This work

3. Photoredox catlysed benzylic azidation

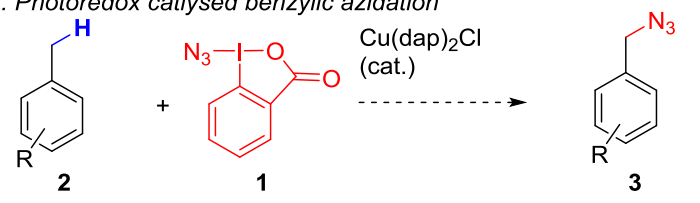

substrates using the Zhdankin regent under copper catalysis. ${ }^{8}$ Further investigation established that both $\mathrm{Cu}(\mathrm{dap})_{2} \mathrm{Cl}$ and visible light were required for efficient reaction, with common photoredox catalysts such as $\mathrm{Ru}(\mathrm{bpy})_{3} \mathrm{Cl}_{2}$ (entry 2) and $\operatorname{Ir}(\text { ppy })_{3}$ (entry 3 ) being ineffective. The simple copper salt $\mathrm{CuBr}$, however, did give reasonable conversions (entry 4). Low levels of background reaction were noted in the absence of catalyst but presence of light, and absence of light but presence of $\mathrm{Cu}$ (dap) ${ }_{2} \mathrm{Cl}$ (entries 5 and 7). No catalyst and no light produced no reaction (entry 6). Reducing the stoichiometry of the starting $p$-xylene $\mathbf{2}$ gave a corresponding reduction in yields (entry 8 ), with 5 equivalents giving $39 \%$ of the azide 3a. We could, however, recover the unreacted $\mathrm{C}-\mathrm{H}$ component in each case. 
Table 1. Reaction optimization ${ }^{\mathrm{a}}$
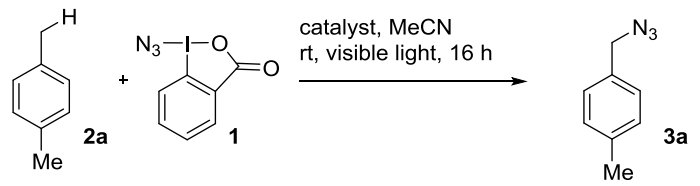

\begin{tabular}{|c|c|c|c|}
\hline entry & catalyst & notes & yield $(\%)^{b}$ \\
\hline 1 & $\begin{array}{l}\mathrm{Cu}(\text { dap })_{2} \mathrm{Cl} \\
(0.5 \mathrm{~mol} \%)\end{array}$ & & 80 \\
\hline 2 & $\begin{array}{c}\mathrm{Ru}(\mathrm{bpy})_{3} \mathrm{Cl}_{2} \\
(1 \mathrm{~mol} \%)\end{array}$ & & 0 \\
\hline 3 & $\begin{array}{c}\operatorname{Ir}(\text { ppy })_{3} \\
(1 \mathrm{~mol} \%)\end{array}$ & & 0 \\
\hline 4 & $\begin{array}{c}\mathrm{CuBr} \\
(0.5 \mathrm{~mol} \%)\end{array}$ & & 55 \\
\hline 5 & $\begin{array}{l}\mathrm{Cu}(\mathrm{dap})_{2} \mathrm{Cl} \\
(0.5 \mathrm{~mol} \%)\end{array}$ & dark & 29 \\
\hline 6 & none & dark & 0 \\
\hline 7 & none & light & 17 \\
\hline 8 & $\begin{array}{l}\mathrm{Cu}(\text { dap })_{2} \mathrm{Cl} \\
(0.5 \mathrm{~mol} \%)\end{array}$ & 5 equiv of xylene & 39 \\
\hline
\end{tabular}

a Reaction conditions: Catalyst, 1-azido- $1 \lambda^{3}-$ benzo[ $d][1,2]$ iodaoxol-3(1H)-one $(1.0$ equiv, $0.50 \mathrm{mmol})$ and degassed MeCN / para-xylene (5 mL, 1:1) irradiated with a $30 \mathrm{~W}$ fluorescent bulb (1 cm distance) for $16 \mathrm{~h} .{ }^{\mathrm{b}}$ Isolated yields.

Scheme 2. Primary azide substrate scope $\mathrm{e}^{\mathrm{a}, \mathrm{b}}$

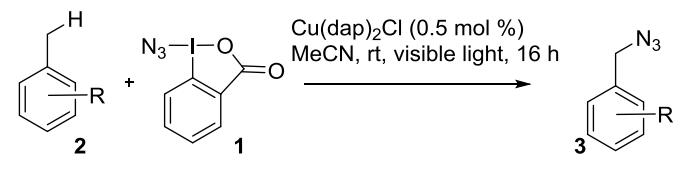

\section{Primary azides}<smiles>N#Cc1ccccc1</smiles>

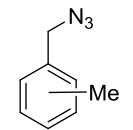

3b, $61 \%$ 3c, o-Me: $77 \% \quad$ 3e, $\mathrm{R}=\mathrm{Br}: 81 \%$ 3d, $m-\mathrm{Me}: 76 \% \quad$ 3f, $\mathrm{R}=\mathrm{I}: 22 \%$ 3a $p$-Me: $80 \% \quad 3 g, \mathrm{R}=\mathrm{Ph}: 60 \%$
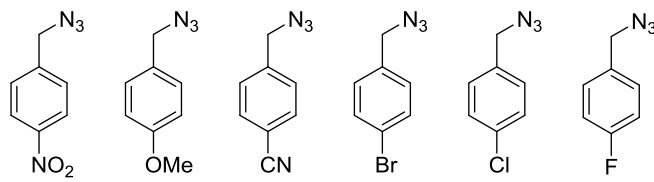

3j, $50 \%$
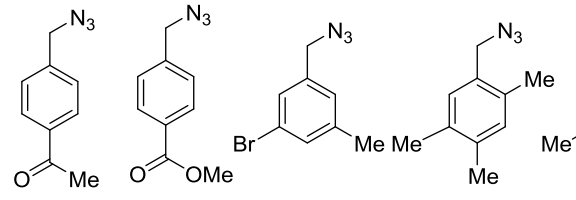

$3 \mathbf{s}, 78 \%$

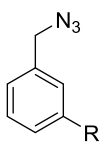

$3 \mathrm{~h}, \mathrm{R}=\mathrm{Cl}: 68 \%$

$3 i, R=F: 39 \%$

$3 p, 35 \%$

$3 q, 50 \% \quad 3 r, 48 \%$

3t, $91 \%$

a General conditions for azidation: $\mathrm{Cu}(\mathrm{dap}) \mathrm{Cl}_{2}(0.5 \mathrm{~mol} \%)$, 1-azido-1 $\lambda^{3}$-benzo $[d][1,2]$ iodaoxol-3(1H)-one $(\mathbf{1}, 1.0$ equiv, $0.50 \mathrm{mmol}$ ), degassed $\mathrm{MeCN} /$ substrate 2 (5 mL, 1:1) irradiated with a $30 \mathrm{~W}$ fluorescent bulb $(1 \mathrm{~cm}$ distance $)$ for $16 \mathrm{~h} .{ }^{\mathrm{b}}$ Isolated yields.

Investigation of the reaction scope (Scheme 2) established a broad reactivity profile, encompassing halogenated (para and meta-Cl, para, meta, and ortho-Br, para and meta-F, para-I), electron rich (para-OMe, para-Me, ortho-Ph) and even some electron poor (para- $\mathrm{NO}_{2},-\mathrm{CN},-\mathrm{CO}_{2} \mathrm{Me}$, and $-\mathrm{COMe}$ ) toluenes (Scheme 2). Yields were generally good to excellent for electron-rich, brominated and chlorinated substrates, with electron-poor toluenes reacting in moderate yield. Direct azidation of this latter category of deactivated substrates, however, has rarely been reported in the literature. ${ }^{13 b}$ Substitution on each of the ortho, meta and para positions was probed for xylene isomers, with successful azidation being observed in each case (3a, 3c and 3d), with mesitylene and durene being similarly productive (3s and $\mathbf{3 t}$ ).

Following those positive results with primary substrates, we explored the possibility of substitution at secondary and tertiary benzylic positions, and were pleased to find smooth transformation of diphenylmethane (3u), ethylbenzene $(3 \mathbf{v})$, 1,4-diethylbenzene $(\mathbf{3 w})$, and tri-isopropylbenzene $(\mathbf{3 x})$ in good yield (Scheme 3).

Scheme 3. Secondary and tertiary azide synthesis ${ }^{a}$
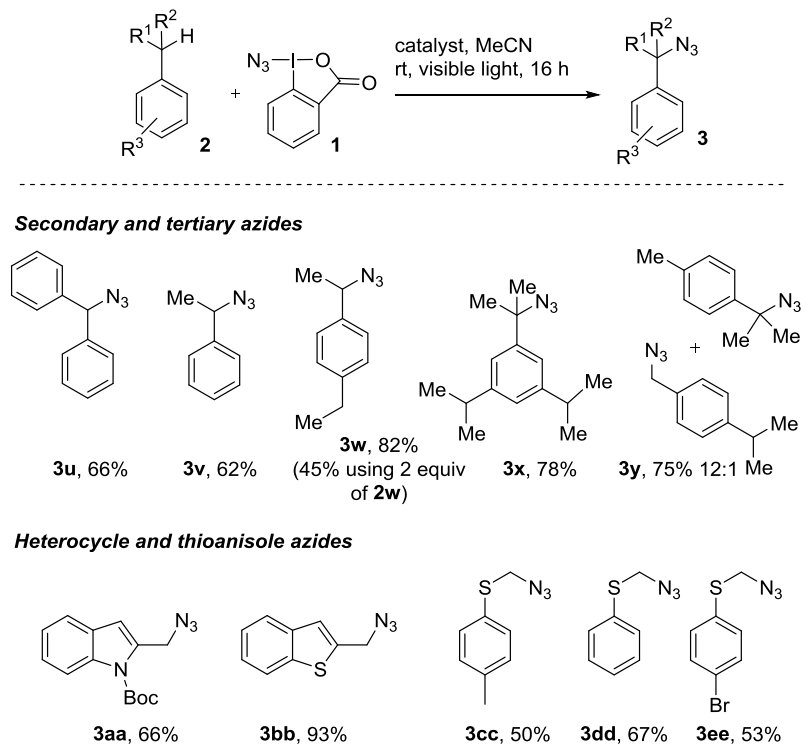

Synthesis of Rufinamide

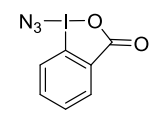

$$
\begin{aligned}
& \text { 1. } \mathrm{CuSO}_{4} \cdot\left(\mathrm{H}_{2} \mathrm{O}\right)_{5}(1 \mathrm{~mol} \%) \\
& \text { ascorbic acid }(10 \mathrm{~mol} \%) \\
& \text { EtOH, rt, } 72 \mathrm{~h}
\end{aligned}
$$

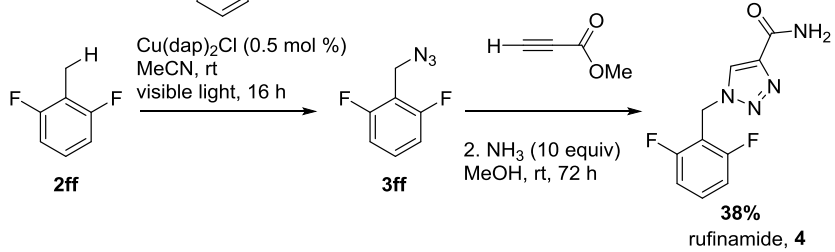

${ }^{a}$ General conditions for azidation: $\mathrm{Cu}(\operatorname{dap}) \mathrm{Cl}_{2}(0.5 \mathrm{~mol} \%)$, 1-azido-1 $\lambda^{3}$-benzo $[d][1,2]$ iodaoxol-3(1H)-one $(\mathbf{1}, 1.0$ equiv, $0.50 \mathrm{mmol}$ ), degassed MeCN / substrate 2 (5 mL, 1:1) irradiated with a $30 \mathrm{~W}$ fluorescent bulb $(1 \mathrm{~cm}$ distance $)$ for $16 \mathrm{~h} .{ }^{\mathrm{b}}$ Isolated yields.

Lowering the stoichiometry to two equivalents, in the case of 1,4-diethylbenzene, gave a $45 \%$ yield of the azide $3 \mathbf{w}$. Cy- 
mene azidation was selective for the tertiary azide over the primary, in line with expectations of a radical mechanism and cleavage of the weaker tertiary $\mathrm{C}-\mathrm{H}$ bond (vide infra). Finally, we examined some heterobenzylic substrates and could successfully synthesize the indole (3aa) and benzothiophene (3bb) azides in good to excellent yield, respectively.

In the course of substrate screening we uncovered some anomalous behavior for the $p$-thiomethoxytoluene 2cc. In contrast to the $p$-methoxy analog $(\mathbf{2 k})$, the major product $3 \mathbf{c c}$ occurred from azidation at the SMe group (50\%), with only $10 \%$ azidation taking place at the tolyl position. The radicalstabilizing effect of sulfur was exemplified through azidation of thioanisole 3dd and $p$-bromo-thioanisole 3ee, compounds previously prepared by Pummerer-type chlorination and azide addition. The $\mathrm{N}_{3} \mathrm{CH}_{2} \mathrm{SAr}$ moiety has been reported as a synthon for $\mathrm{NH}_{2}{ }^{+}$, reacting with aryl Grignard reagents to give anilines after hydrolysis. ${ }^{14}$

We could apply the direct azidation methodology in the synthesis of a drug, rufinamide (4), an anti-epileptic medication from Novartis. Previous routes utilize benzylic halogenation and displacement with sodium azide, both at elevated temperatures. ${ }^{15}$ Here, we could effect direct benzylic azidation of 1,3difluorotoluene $\mathbf{2 f f}$ under benign conditions to give the azide 3ff in 38\% yield, which underwent $\mathrm{Cu}$-catalyzed 1,3-dipolar addition and aminolysis in quantitative yield to afford rufinamide 4 , without recourse to halogenation reagents or sodium azide in the synthetic sequence.

Radical chain reactions have been implicated in $\mathrm{C}-\mathrm{H}$ azidation reactions of $\mathbf{1}$ since Zhdankin's initial work on the reagent, initiated by homolysis of the weak I-N bond. ${ }^{3,7 b, 10,16}$ Here, it is likely that electron transfer from the photoexcited $\mathrm{Cu}(\text { dap })_{2}{ }^{+}$ reductively cleaves $\mathbf{1}$ to generate a source of azide radicals, which can then abstract a benzylic hydrogen atom from substrate 2 . The reaction is then propagated through benzyl radical $\mathbf{6}$ abstracting azide from 1, generating the chain-carrying iodane radical $\mathbf{7}$ which can abstract a hydrogen atom from benzylic substrate 2 . Control reactions with radical quenchers TEMPO and BHT were found to suppress the reaction, consistent with the proposed radical chain process.

Scheme 4. Proposed mechanism
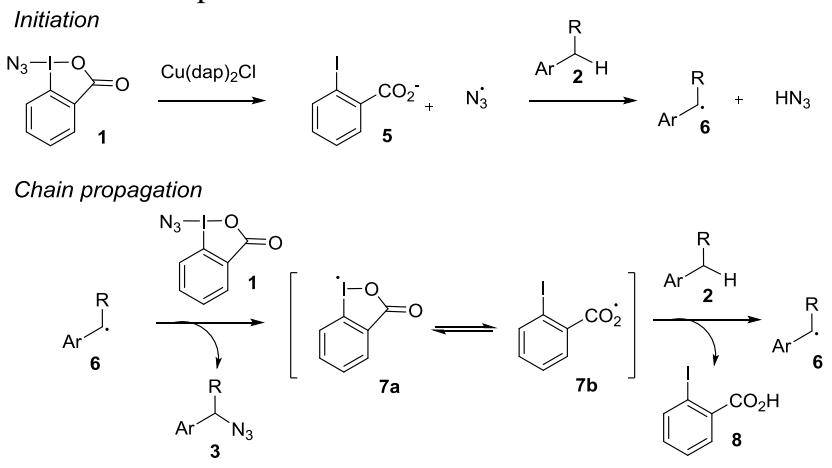

To conclude, we have described a direct azidation of benzylic $\mathrm{C}-\mathrm{H}$ positions that occurs at room temperature, under mild conditions, using an earth-abundant first row transition metal photoredox catalyst. The scope of the reaction is broad and tolerant of many functional groups, encompassing primary, secondary and tertiary benzylic positions, and a formal azidoPummerer pathway has been identified for thioanisole derivatives. Further photoredox-catalysed azidation transformations are being investigated in our laboratory.

\section{ASSOCIATED CONTENT}

\section{Supporting Information}

Experimental procedures and characterization data for all new compounds are available in the Supporting Information. This material is available free of charge via the Internet at http://pubs.acs.org.

\section{AUTHOR INFORMATION}

\section{Corresponding Author}

* Michael.greaney@ manchester.ac.uk

\section{Author Contributions}

The manuscript was written through contributions of all authors. / All authors have given approval to the final version of the manuscript.

\section{ACKNOWLEDGMENT}

We thank the EPSRC and AstraZeneca for funding. Mr Christopher Teskey (University of Manchester) is thanked for helpful discussions.

\section{REFERENCES}

(1) Paria, S.; Reiser, O. ChemCatChem. 2014, 6, 2477-2483.

(2) a) Pirtsch, M.; Paria, S.; Matsuno, T.; Isobe, H.; Reiser, O. Chem. Eur. J. 2012, 18, 7336-7340. b) Paria, S.; Pirtsch, M.; Kais, V.; Reiser, O. Synthesis 2013, 45, 2689-2698. c) Hernandez-Perez, A. C.; Vlassova, A.; Collins, S. K. Org. Lett. 2012, 14, 2988-2991. d) Hernandez-Perez, A. C.; Collins, S. K. Angew. Chem. Int. Ed. 2013, 52, 12696 -12700. e) Baralle, A.; Fensterbank, L.; Goddard, J.-P.; Ollivier, C. Chem. Eur. J. 2013, 19, 10809-10813. f) Tang, X.-J.; Dolbier Jr, W. R. Angew. Chem. Int. Ed. 2015, 54, 4246-4249. g) Bagal, D. B.; Kachkovskyi, G.; Knorn, M.; Rawner, T.; Bhanage, B. M.; Reiser. O.; Angew. Chem. Int. Ed. 2015, 54, 6999-7002. h) Sagadevan, A.; Ragupathi, A.; Hwang, K. C. Angew. Chem. Int. Ed. 2015, 54, 1389613901. i) Kainz, Q. M.; Matier, C. D.; Bartoszewicz, A.; Zultanski, S. L.; Peters, J. C.; Fu, G. C. Science 2016, 351, 681-684.

(3) a) Zhdankin, V. V.; Kuehl, C. J.; Krasutsky, A. P.; Formaneck, M. S.; Bolz, J. T. Tetrahedron Lett. 1994, 35, 9677-9680. b) Krasutsky, A. P.; Kuehl, C. J.; Zhdankin, V. V. Synlett 1995, 1081-1082. c) Zhdankin, V. V.; Krasutsky, A. P.; Kuehl, C. J.; Simonsen, A. J.; Woodward, J. K.; Mismash, B.; Bolz, J. T. J. Am. Chem. Soc. 1996, $118,5192-5197$.

(4) Kern, J.-M.; Sauvage, J.-P. Chem. Commun. 1987, 546-548.

(5) Fumagalli, G.; Rabet, P. T. G.; Boyd, S.; Greaney, M. F. Angew. Chem. Int. Ed. 2015, 54, 11481-11484.

(6) Review of C-H azidation: Huang, X.; Groves, J. T. ACS Catalysis, 2016, 6, 751-759.

(7) a) Sharma, A.; Hartwig, J. F. Nature, 2015, 517, 600-604. b) Wang, Y.; Li, G.-X.; Yang, G.; Hea, G.; Chen, G. Chem. Sci. 2016, DOI: $10.1039 / \mathrm{c} 5 \mathrm{sc} 04169 \mathrm{~d}$.

(8) Fan, Y.; Wan, W.; Ma, G.; Gao, W.; Jiang, H.; Zhu, S.; Hao, J. Chem. Commun. 2014, 50, 5733-5736.

(9) a) Deng, Q. H.; Bleith, T.; Wadepohl, H.; Gade, L. H. J. Am. Chem. Soc. 2013, 135, 5356-5359. b) Vita, M. V.; Waser, J. Org. Lett. 2013, 15, 3246-3249.

(10) Shinomoto, Y.; Yoshimura, A.; Shimizu, H.; Yamazaki, M.; Zhdankin, V. V.; Saito, A. Org. Lett. 2015, 17, 5212-5215.

(11) a) Zhang, B.; Studer, A. Org. Lett. 2013, 15, 4548-4551. b) Yin, H.; Wang, T.; Jiao, N. Org. Lett. 2014, 16, 2302- 2305. c) Lu, M.-Z.; Wang, C.-Q.; Loh, T.-P. Org. Lett., 2015, 17, 6110-6113. d) Ouyang, X.-H.; Song, R. -J.; Liu, Y.; Hu, M.; Li, J.-H. Org. Lett. 
2015, 17, 6038-604. e) Yuan, Y.-A.; Lu, D.-F.; Chen, Y.-R.; Xu, H. Angew. Chem., Int. Ed. 2016, 55, 534-538.

(12) Recent C-H azidations with alternative azide sources: a) Tang C.; Jiao, N. J. Am. Chem. Soc. 2012, 134, 18924-18927. b) Huang, X.; Bergsten, T. M.; Groves, J. T. J. Am. Chem. Soc. 2015, 137, 5300-5303. c) Zhang, X.; Yang, H.; Tang, P. Org. Lett. 2015, 17, 5828-5831. d) Kamijo, S.; Watanabe, M.; Kamijo, K.; Tao, K.; Murafuji, T. Synthesis, 2015, 48, 115-121.

(13) a) Guy, A.; Lemor, A.; Doussot, J.; Lemaire, M. Synthesis, 1988, 900-902. b) Kita, Y.; Tohma, H.; Takada, T.; Mitoh, S.; Fujita, S.; Gyoten, M. Synlett 1994, 427-428. c) Pedersen, C. M.; Marinescu, L. G.; Bols, M. Org. Biomol. Chem., 2005, 3, 816-822. d) Chouthaiwale, P. V.; Suryavanshi, G.; Sudalai, A. Tetrahedron Lett. 2008, 49,
6401-6403. e) Chen, H.; Yang, W.; Wu, W.; Jiang, H. Org. Biomol. Chem., 2014, 12, 3340-3343.

(14) Trost, B. M.; Pearson, W. H. J. Am. Chem. Soc. 1981, 103, 2483-2485.

(15) Mudd, W. H.; Stevens, E. P. Tetrahedron Lett. 2010, 51, 3229-3231.

(16) For other examples of iodinane radical propagating chain processes through C-H abstraction, see: a) Magnus, P.; Roe, M. B.; Hulme, C. Chem. Commun. 1995, 263-265. b) Ochiai, M.; Ito, T.; Takahashi, H.; Nakanishi, A.; Toyonari, M.; Sueda, T.; Goto, S.; Shiro, M. J. Am. Chem. Soc., 1996, 118, 7716-7730. c) Moteki, S. A.; Usui, A.; Zhang, T.; Solorio Alvarado, C. R.; Maruoka, K. Angew. Chem. Int. Ed. 2013, 52, 8657-8660. 


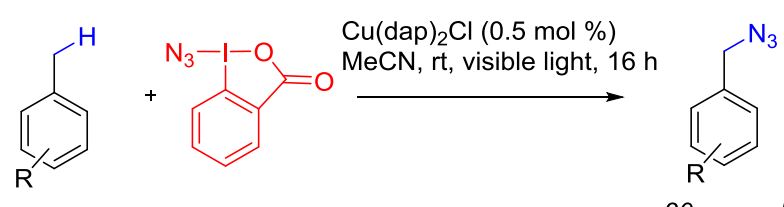

30 examples 